\title{
PREPARATION AND CHARACTERISATION OF ALUMINA NANOCOMPOSITES WITH ARAMID FIBRE AND HYBRID FIBRE REINFORCEMENTS
}

\author{
S.Charvani ${ }^{1}$, Ch.Gopal Reddy ${ }^{2}$ \\ ${ }^{1}$ Research Scholar, Department of Physics, University College of Science, Osmnania University, Hyderabad \\ ${ }^{2}$ Professor, Department of Physics, University College of Science, Osmnania University, Hyderabad
}

\begin{abstract}
The requirement of light weight and high strength materials are ever increasing in the industry. Lot of research is going on worldwide for improvement of mechanical properties of light weight non-metallic composites. Researchers are trying to meet the industrial requirements by modifying properties of composite materials by making nanocomposites. Nanocomposites are formed by mixing two or more dissimilar materials and adding nanoparticles in order to control and develop new and improved materials and their properties. The properties of composites depend not only upon the individual components used but also upon the morphology and the interfacial characteristics of the ingredients. This novel feature forms the basis of hypothesis to be investigated.

In the investigation for high strength materials, laminates of epoxy resin and nanoparticles of $\mathrm{Al}_{2} \mathrm{O}_{3}$ as filler are used with Aramid fibre, hybrid of carbon and aramid fibre as reinforcement are produced. Nanoparticles of $\mathrm{Al}_{2} \mathrm{O}_{3}$ of 20-30nm size are first dispersed in methanol by mechanical stirring. The solution is further sonicated for effective dispersion of nanoparticles. The mixture of methanol and $\mathrm{Al}_{2} \mathrm{O}_{3}$ nanoparticles are mixed in preheated Epoxy resin and mechanically stirred. During mixing some of the methanol is evaporated. Further, the remaining methanol is removed by heating and drying. Then, Hardener is mixed with the mixture of epoxy- $\mathrm{Al}_{2} \mathrm{O}_{3}$ and laminates are prepared. The laminates are cut to the required size of test samples for mechanical tests. It is observed that the mechanical properties are improved with the addition of nanoparticles of $\mathrm{Al}_{2} \mathrm{O}_{3}$.
\end{abstract}

Keywords: nanocomposites, bath sonication, $\mathrm{Al}_{2} \mathrm{O}_{3}$ Nanoparticles

\section{INTRODUCTION}

Composite materials are fabricated or naturally occurring materials made from two or more constituent materials which have different physical, chemical properties but which remain separate and distinct at the macroscopic or microscopic level within the material. Commercial materials commonly used are glass fibre or carbon fibres or aramid fibre in matrices of thermosetting polymers, such as epoxy resin or polyester resin etc. The objective of preparing composite materials is to make a component which is strong and stiff with low density.

The matrix material surrounds and supports the reinforcement materials by maintaining their relative positions. The reinforcements impart their physical and mechanical properties to enhance the properties of the composite materials. The matrix material can be introduced to the reinforcement before or after the reinforcement material is placed into the mould cavity or onto the mould surface. Then the composite is allowed to settled and cured.

The matrix material experiences combined effects of strength and low weight. Most commercially produced composites use a polymer matrix material often called a resin solution. There are many polymers available depending upon the starting raw ingredients. The most common are known as polyester, vinyl ester, epoxy resin, phenolic, polyamide, polypropylene, and others.

In matrix-based composites, the matrix serves two major purposes they are binding the reinforcement material in fixed position and deforming to distribute the developed stresses among the constituent reinforcement materials under the applied forces.

The reinforcement materials are often fibres but also commonly ground minerals. Fibers or particles embedded in matrix of another material would be the best example of modern-day composite materials, some of them are also used in structural applications. Reinforcing materials generally withstand maximum load and serve the desirable properties.

Reinforcements for the composites are fabrics, fibers, particles. Fibers are essentially characterized by one very long axis with other either circular or near circular shape. Particles have no axis and so does their shape. Fibres are also woven mats used in preparation of composites.

A reinforcement that must be stronger and stiffer than the matrix and capable of challenging failure mechanism leads to the advantage of the composite. This means that the ductility property should be minimum. 
Fibers are the important class of reinforcements, as they satisfy the desired requirements and transfer strength to the matrix, influencing and enhancing their properties as desired.

Glass fibers are the earliest known fibers used to reinforce materials in composites. Ceramic and metal fibers were subsequently found out for use in composites and put to extensive use, to make composites strong, stiffer more resistant to heat.

Fibers fall short of ideal performance due to several factors. The effectiveness of a fiber composite is influenced by length of fibre, shape, orientation along the direction of applied force, composition of the fibers and the properties of the matrix.

The orientation of the fiber in the matrix is an indication of the strength of the composite and the strength is greatest along the longitudinal direction of fiber. This doesn't mean the longitudinal fibers can take the same amount of load irrespective of the direction in which it is applied. Optimum performance from composites with longitudinal fibers can be obtained if the load is applied along its direction. The angle of loading may drastically affect the strength of the composite.

Choice of fabrication method of composite depends on matrix properties and the effect of matrix on properties of reinforcement fibre. One of the important considerations in the selection and fabrication of composites is that the constituents should be chemically inert non-reactive.

\section{EXPERIMENTAL METHODOLOGY}

\subsection{Materials}

The materials used in preparation of specimens are $\mathrm{Al}_{2} \mathrm{O}_{3}$ nanopower with average particle size of 20-30 nm. Methanol is used for dispersion of nanopowder. The epoxy resin used is Araldite- LY 556 and hardener used is AmineHY 951. Epoxy resin and hardener are mixed in the ratio of 10:1. The reinforcement fibre used in preparation of the nanocomposite laminates are (i)Aramid woven mat and (ii) hybrid of carbon and aramid woven mat.

\section{Preparation of Nanocomposites of Epoxy Resin-}

\section{Alumina Nanopowder:}

There are many techniques which can be used to incorporate the nano-sized particles into the polymer matrix. In the literature it was found that the nano-sized alumina particles could be dispersed homogeneously with the aid of methanol solvent. Following the previous research works, firstly, the dried alumina powders were dispersed into methanol followed by stirrer mixing for 30 minutes. The mixture was placed in the sonicater bath for 30 minutes to break excessive aggregates of nanopower. The alumina nanopowder and methanol mixture was stirred continuously at room temperature for five hours. To promote better wetting between the epoxy resin and alumina-ethanol mixture, epoxy resin was pre-heated at $70^{\circ} \mathrm{C}$ for 30 minutes in oven before adding into the alumina-methanol mixture. Then, the entire mixtures were mechanically stirred using a mechanical stirrer for one hour. After this, methanol was removed from the epoxy-alumina mixture by heating at above boiling point of methanol at around $70^{\circ} \mathrm{C}$ and drying . The epoxy-alumina mixture is further dried by placing it into the oven at around $70^{\circ} \mathrm{C}$ for an hour. Lastly, the hardener was added into the epoxy- alumina mixtures in a stoichiometric ratio of 10:1. The epoxy-alumina and hardener mixture were properly stirred for uniform mixing.

Finally the epoxy- alumina mixture was poured into the mold. Glass mould was used for preparation of the composite laminates. Mold releasing agent was applied on the inner surface of the glass mould for quick and easy release of the composite laminate. The calculated amount of epoxy resin and hardener (ratio of $10: 1$ by weight) was thoroughly mixed by stirring with taking care in preventing air entrapment. After applying releasing agent on a glass mould, resin mixure is introduced to half of the final thickness of the laminate layer. One layer of fibre mat is placed over the resin mixture in the mould. The remainder of the mixture was then poured over the fibre mat already placed in the mold. Care was taken to avoid entry and formation of air bubbles. Finally, on the mould pressure was applied from the top by placing with another glass plate with weights to obtain flat laminate of $3 \mathrm{~mm}$ thickness required for the ASTM standard tests. During application of pressure on the mould some amount of epoxy and hardener mixture squeezes out of the mould. Care has been taken to consider this loss of epoxy mixture during preparation so that a constant thickness of sample could be prepared. This procedure was followed for preparation of aramid, hybrid of aramid and carbon fibres. The mold was allowed to cure at room temperature for $24 \mathrm{hrs}$. After $24 \mathrm{hrs}$ the samples were taken out of the mold, and kept in hot air oven for curing at $80^{\circ} \mathrm{C}$ for $10 \mathrm{hrs}$. After curing in oven, the cured epoxy alumina nanocomposite laminates were cut into required sizes for various mechanical tests. The materials used, stirring, sonication process and the samples are show in fig. 1 through fig.5.

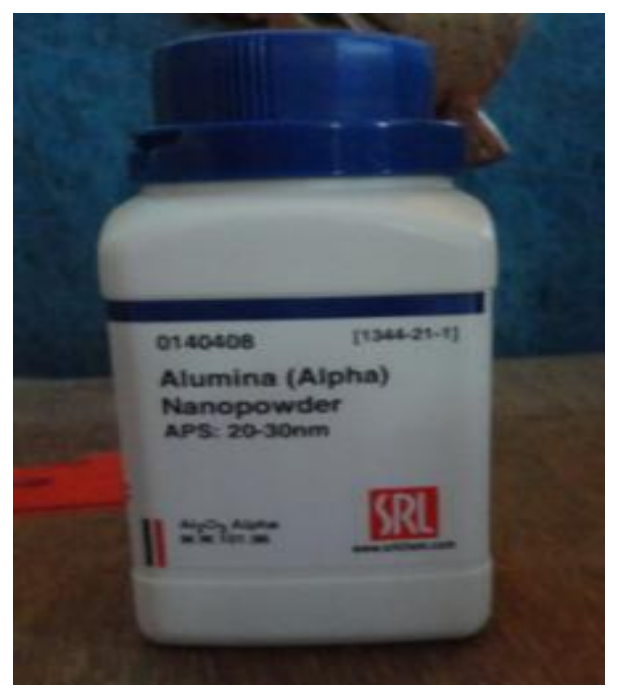

Fig.1.Alumina Nanopowder 


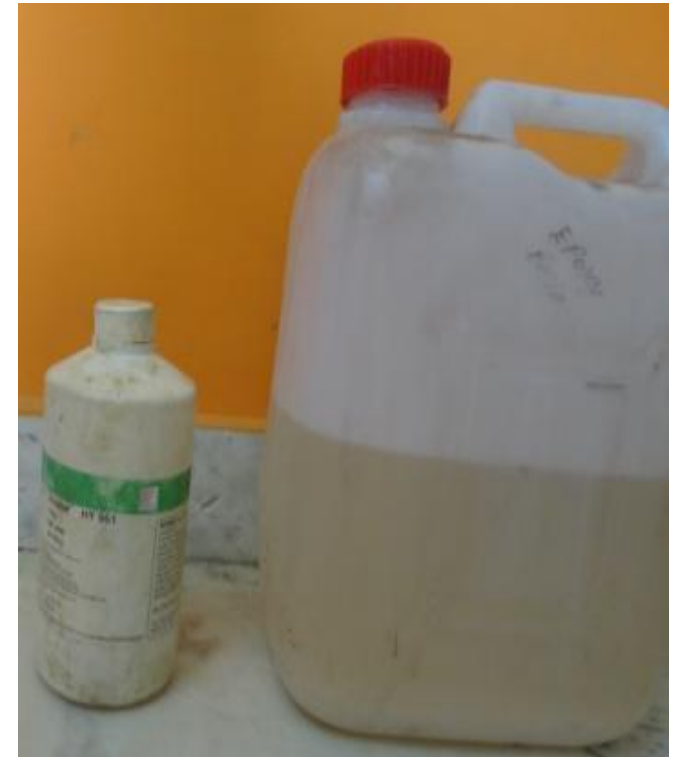

Fig.2 Hardener and resin

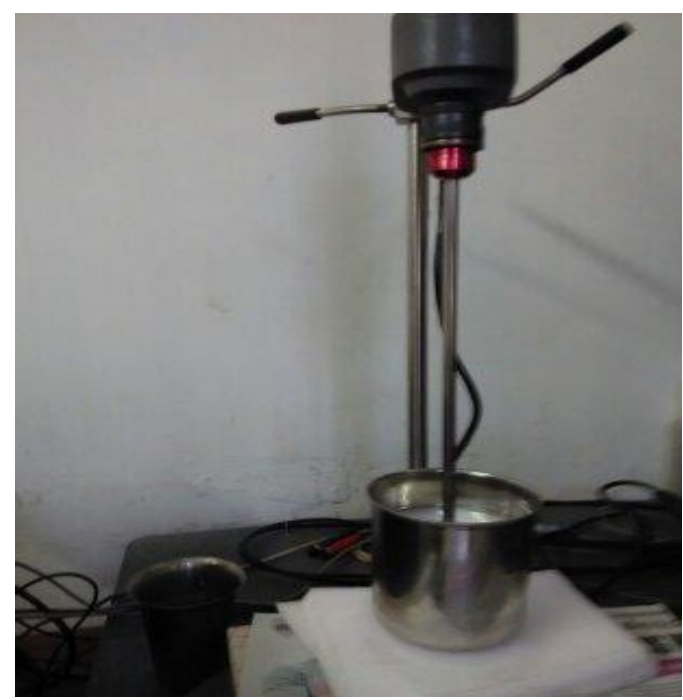

Fig.3 Mechanical Stirrer

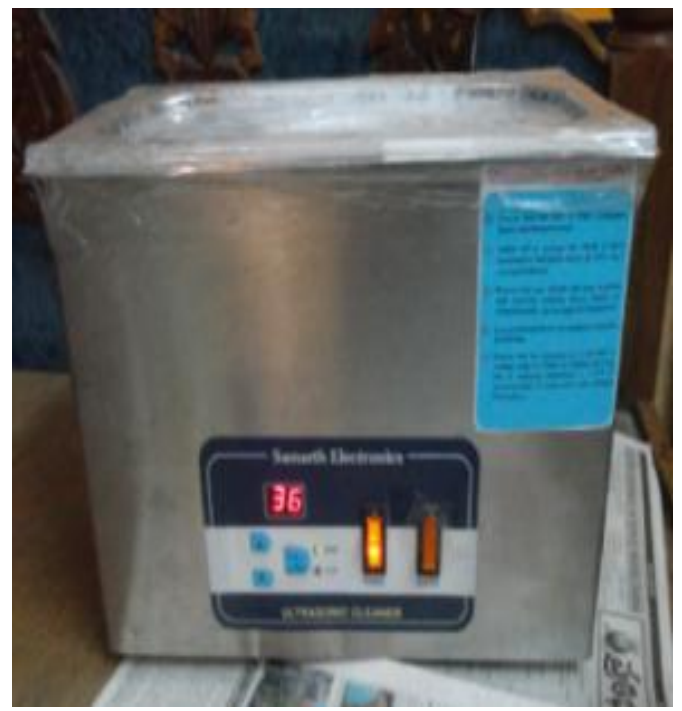

Fig. 4 Soncation bath

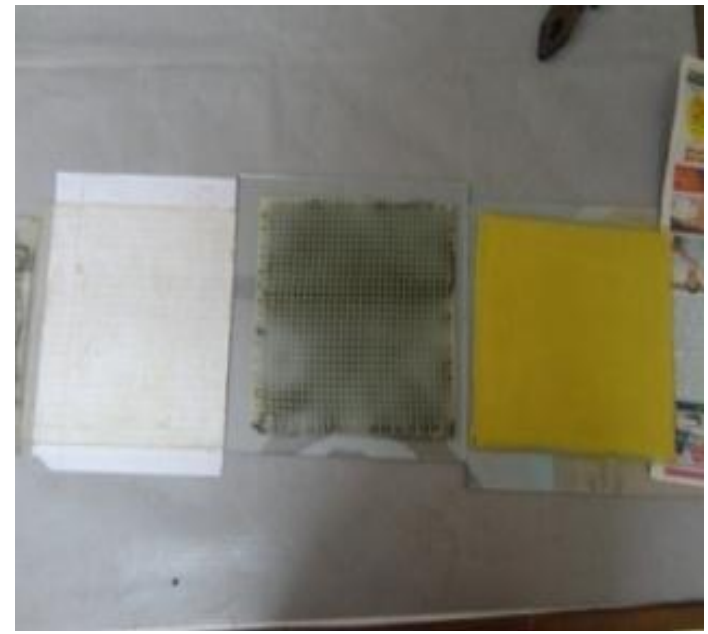

Fig.5 Composite laminates

\section{RESULTS}

The laminates are prepared with reinforcement of Aramid fibre woven mat, hybrid of carbon and aramid woven mat, and plane composites with and without Alumina nanopower filler addition. The specimens for mechanical tests are cut from the composite laminates as per ASTM standard sizes. The specimens are tested in Universal Testing Machine and Izod Impact Testing Machine for tensile, flexural and impact tests respectively.

Testing on reinforcement woven fabric composites give similar properties in perpendicular direction in the plane of laminate than unidirectional composites. Various mechanical tests viz., Tensile test, flexural test and impact tests are carriedout on the specimens prepared from the laminates.

\subsection{Tensile test}

The tensile test is conducted on flat specimens cut from the laminates as per ASTM D638 standard and are shown in fig.6. The most commonly used specimen geometries are the straight-sided specimen with end tabs. Uni-axial load is applied through the ends. The test-piece used here was having dimensions according to the standards. The tensile tests were performed on all the three specimens of Plane, Aramid, and hybrid of Aramid and Carbon fibre woven mat composites as per test standards.

It is observed that the tensile strength properties are enhanced for hybrid composites compared to plane and aramid composites. When $1 \%$ nano particles of $\mathrm{Al}_{2} \mathrm{O}_{3}$ are added the ultimate tensile strength is enhanced for plane and aramid composites. Based on the obtained test results, graphs are prepared and presented in fig.9.

\subsection{Flexural test}

The flexural strength of a material under bending is expressed as the stress on the outermost fibres of a bent test specimen, at the instant of failure. The determination of flexural strength is an important property of any structural material. It is the ability of the composite material to 
withstand bending before reaching the breaking point. Conventionally a three point bend test is conducted for finding out this material property. The flexural test was performed on all the three samples as per ASTM D790 test standards. The specimens are shown in fig. 7 and test results are presented in fig.10. It is observed that the Hybrid and Aramid composites have nearly equal flexural strength.

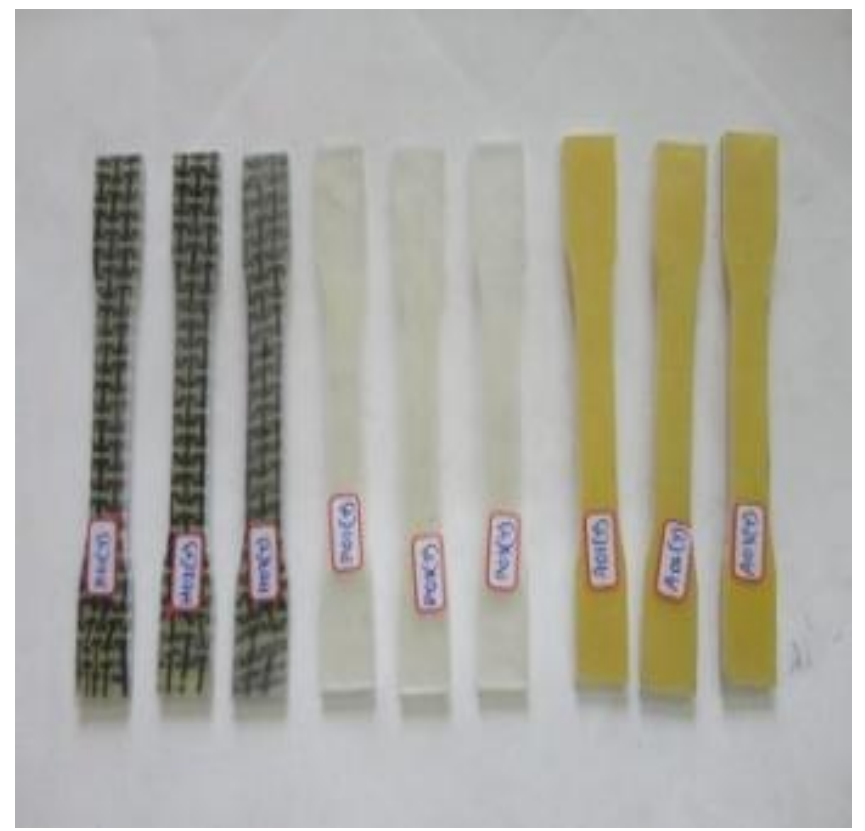

Fig.6 Specimens for Tensile test

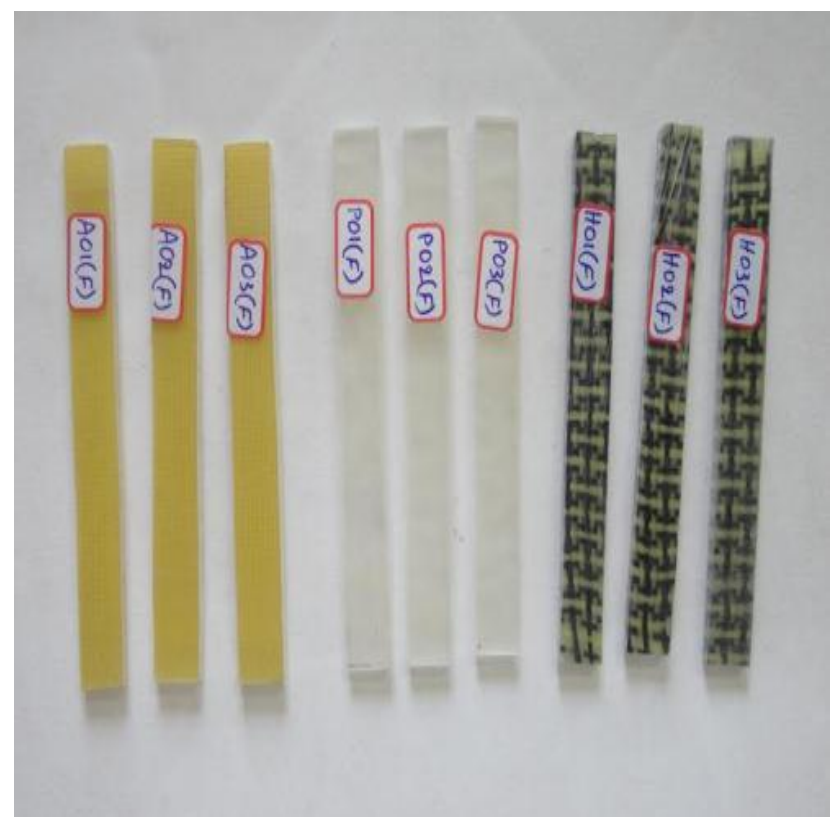

Fig.7 Specimens for Flexural Tests

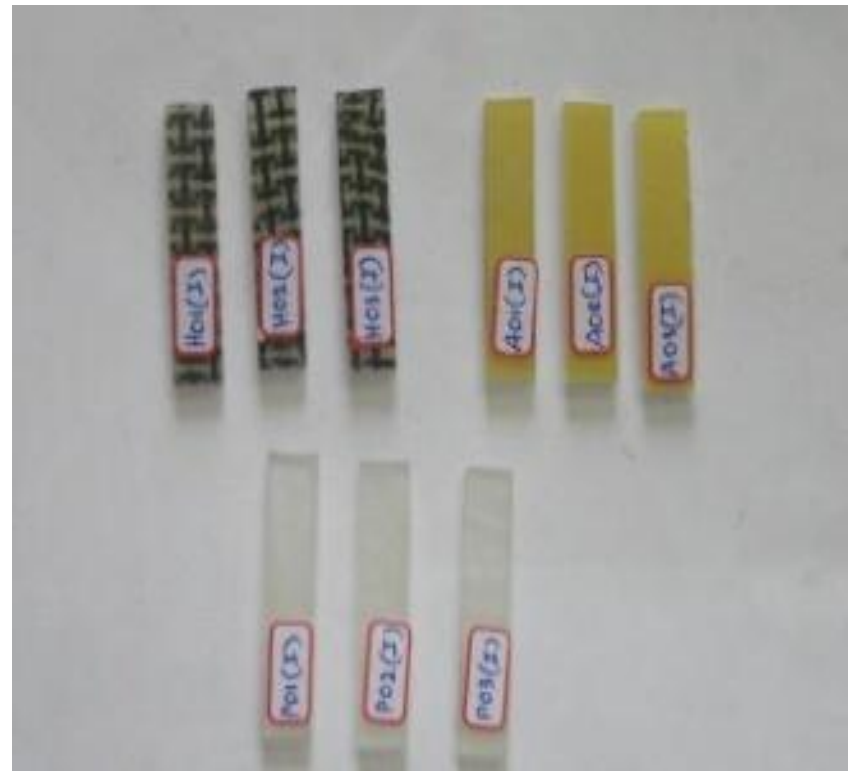

Fig.8 Specimens for Impact Test

\subsection{Impact Test}

The test specimens are prepared as per ASTM D256 and are shown in fig.8. The test involves striking the standard specimen with a specified weight pendulum dropped from the specified height. The amount of energy absorbed in fracturing the test piece is measured and this gives an indication of the toughness of the test material.

This test shows that materials can be classified as either brittle or ductile. A brittle material will absorb a small amount of energy during impact test, a ductile material will absorb a large amount of energy before breakage. The plane composite and Hybrid composites exhibit same impact strength. It is observed that there is no much difference in the impact strength for composites with and without nanoparticles for various fibre materials. The test results are presented in fig. 11 .

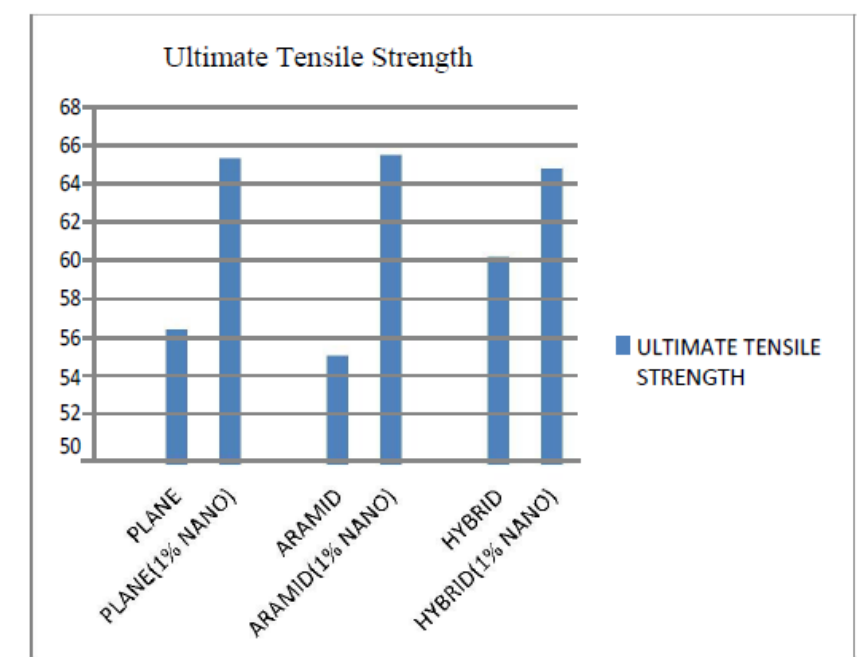

Fig.9 Ultimate Tensile Strength 


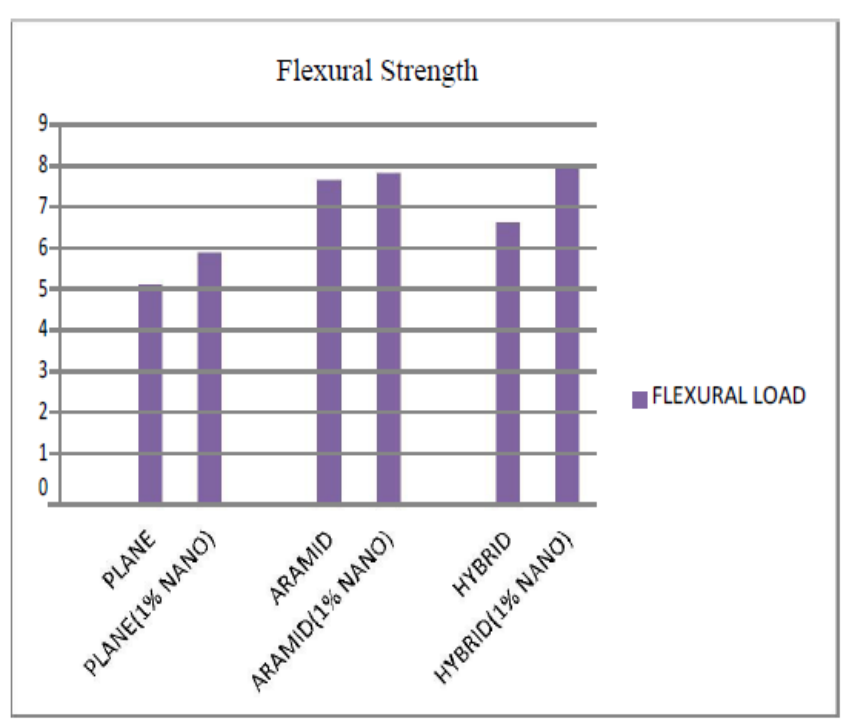

Fig.10 Flexural strength

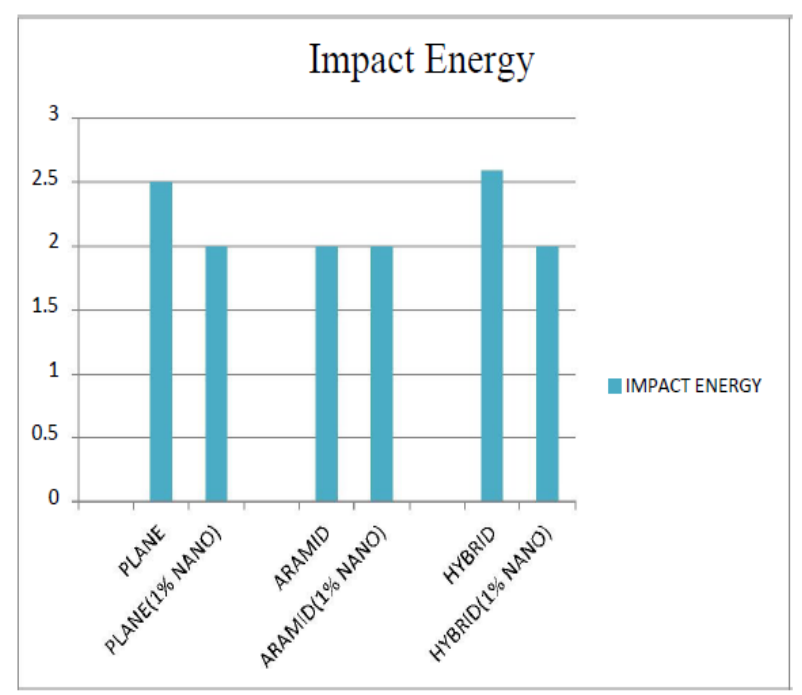

Fig.11 Impact strength

\section{CONCLUSION}

The mechanical tests are conducted on the composites without nano particles and with loading of $1 \% \quad \mathrm{Al}_{2} \mathrm{O}_{3}$ nanoparticles. From the tests the following conclusions drawn.

1. The ultimate tensile strength for aramid composites with $1 \%$ nanoparticle loading is found to be highest among the hybrid and plane composites.

2. The Flexural strength for $1 \%$ nano particle added aramid composites is found to be equally good with the $1 \%$ nano particle added hybrid composites. But the flexural strength of both of these is higher than plane composites. For flexural strength properties, there is no much difference between aramid and hybrid composites with $1 \%$ nanoparticles.

3. In Impact strength properties, there is no much difference for plane, aramid and hybrid with and without nano particles except for plane and hybrid components.

\section{ACKNOWLEDGEMENTS}

The authors would like to acknowledge and express sincere thanks to the OU-DST-PURSE Program for sanctioning and supporting experimentation on composite materials.

\section{REFERENCES}

[1] KVP Chakradhar et al., Epxoy/Polyester blend nanocomposites: Effect of nanoclay on Mehanical, Thermal and Morphological Properties, Malaysian Polymer Journal, Vol.6, No.2, p109-118,2011.

[2] De Lange P.J., Mäder E., Mai K., Young R.J., Ahmad I., Characterization and micromechanical testing of the interphase of aramid - reinforced epoxy composites. Composites Part A (2001) 32: 331-342.

[3] Tewari U.S., Harsha A.P, Häger A.M., Friedrich K., Solid particle erosion of carbon fibre- and glass fibre- epoxy composites, Compos Sci. and Technol. (2003) 63:549-557.

[4] Shah, A.P., Gupta, R.K., Gangarao, H.V.S. and Powell, C.E. (2002). Moisture Diffusion through Vinyl Ester Nanocomposite Made With Montmorillonite Clay, Polym. Eng. Sci., 42(9): 1852-1858.

[5] Giannelis, E.P. (1996). Polymer Layered Silicate Nanocomposite, Adv. Mater., 8(1): 29-35.

[6] LeBaron, P.C., Wang, Z. and Pinnavaia, T.J. (1999). Polymer-layered Silicate Nanocomposites: An Overview, Appl. Clay Sci., 15: 11-29.

[7] Porter, D., Metcalfe, E. and Thomas, M.J.K. (2000). Nanocomposites Fire Retardant - A Review, Fire Mater., 24: 45-52.

[8] Alexandre, M. and Dubois, P. (2000). Polymerlayered Silicate Nanocomposites: Preparation, Properties and Use of a New Class of Materials, Mat. Sci. and Eng., 28: 1-63.

[9] Messersmith, P.B. and Giannelis, E.P. (1995). Synthesis and Barrier Properties of Poly "caprolactone Layered Silicate Nanocomposite, J. Polym. Sci. Polym. Chem. Edn., 33: 1047-1057.

[10] Kornmann, X., Berglund, L.A., Sterte, J. and Giannelis, E.P. (1998). Nanocomposites Based on Montmorillonite and Unsaturated Polyester, Polym. Eng. Sci., 38(8): 1351-1358. 